\section{Commentary: Deepening our understanding of acute kidney injury after cardiac surgery: New insights into prediction of persistent acute kidney injury and implications for management}

\author{
Juan N. Pulido, MD
}

Acute kidney injury (AKI) is a dreaded and relatively common complication after cardiac surgery. Even mild forms of AKI have potentially adverse long-term effects. ${ }^{1}$ This has been globally recognized, and as a result, efforts to understand and treat cardiac-surgery-associated AKI (CSAAKI) have been a growing trend. These include AKI prevention and hemodynamic optimization efforts, and more recently, stratification of the AKI spectrum. Specifically, the definition and importance of persistent AKI, and progression to acute kidney disease; 2 recently proposed terms that seek to bridge AKI to chronic kidney disease. $^{2}$

It has been demonstrated that persistence of AKI beyond 72 hours after diagnosis is the most predictive for major adverse kidney events as death, renal replacement therapy (RRT), or persistent renal dysfunction, irrespective of the degree of azotemia. Therefore, beyond accurate biomarkers that can predict the development of CSA-AKI, or establish early diagnosis before azotemia, finding predictors of persistent CSA-AKI after a confirmed diagnosis would be ideal. These would complement our therapeutic approach, and could be used as a wakeup call when it comes to

From the Departments of Cardiothoracic Anesthesiology and Critical Care Medicine, Swedish Medical Center, Cherry Hill Campus, US Anesthesia Partners Washington, Seattle, Wash.

Disclosures: The author reported no conflicts of interest.

The Journal policy requires editors and reviewers to disclose conflicts of interest and to decline handling or reviewing manuscripts for which they may have a conflict of interest. The editors and reviewers of this article have no conflicts of interest.

Received for publication March 29, 2021; revisions received March 29, 2021; accepted for publication March 29, 2021; available ahead of print April 2, 2021.

Address for reprints: Juan N. Pulido, MD, Department of Cardiothoracic Anesthesiology and Critical Care Medicine, Swedish Medical Center, Cherry Hill Campus, US Anesthesia Partners Washington, 550 17th Ave, \#680, Seattle, WA 98122 (E-mail: Juan.PulidoSierra@swedish.org).

J Thorac Cardiovasc Surg 2023;165:210-1

$0022-5223 / \$ 36.00$

Copyright (c) 2021 by The American Association for Thoracic Surgery

https://doi.org/10.1016/j.jtcvs.2021.03.098

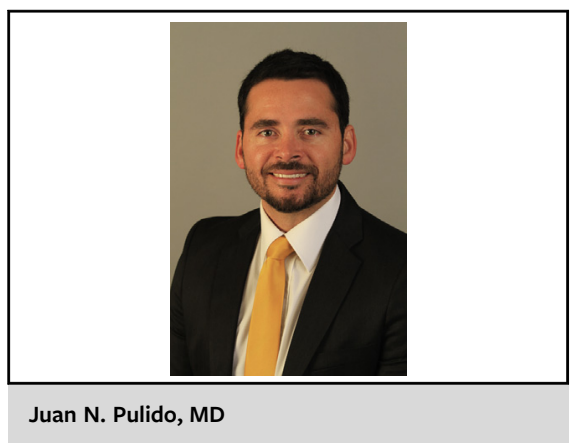

CENTRAL MESSAGE

The use of biomarkers such as urinary CCL14 to predict persistent AKI after cardiac surgery has potential important implications in choosing a therapeutic approach.

activating nephrology consultation, deciding the timing to initiate RRT, and prognostication.

Massoth and colleagues ${ }^{3}$ sought to evaluate whether biomarkers, including urinary C-C motif chemokine ligand 14 (CCL14) were able to predict persistent AKI and major adverse kidney events after cardiac surgery in a prospective observational study. Elevated levels of urinary CCL14 have been shown to predict the persistence and progression of AKI in a large cohort of critically ill patients with moderate and severe AKI (Kidney Disease: Improving Global Outcomes [KDIGO] stage 2 or 3 ), among other biomarkers such as urinary liver-type fatty acid binding protein and Kidney Injury Molecule-1. The authors included 100 patients who developed AKI (KDIGO stage 2 or 3) within 72 hours after cardiac surgery. The primary end point was persistent severe AKI (KDIGO stage 3 ) lasting $>72$ hours after diagnosis. All patients who died or required RRT within 72 hours of inclusion to the study were considered to reach a positive end point as well. Thirty-seven patients (37\%) reached the primary end point. Peak creatinine was higher in the persistent AKI group $(3.74 \pm 1.23 \mathrm{mg} / \mathrm{dL}$ vs $1.63 \pm 1.07 \mathrm{mg} / \mathrm{dL} ; P<.001$ ), also logically, these patients were more likely to undergo complex procedures, had longer cardiopulmonary bypass times, and aortic crossclamp times, in addition to higher severity of illness and increased fluid balance at time of enrollment, in addition to longer ventilator times and intensive care unit length of stay.

The authors found that patients who met the primary end point had significantly elevated urinary concentrations of 
CCL14, and liver-type fatty acid binding protein at time of diagnosis of stage 2 or 3 AKI compared with patients who recovered. Moreover, of the biomarkers examined, urinary CCL14 was the best predictor of persistent AKI with an area under the curve of 0.93 (95\% confidence interval, $0.881-0.979 ; P<.001$ ), and it was not influenced by other comorbidities such as diabetes or preexisting chronic kidney disease.

Although small, this study provides important additional information about what we know of CSA-AKI, specifically when it comes to timing of initiation of RRT when there is not an urgent indication. To this day, timing of RRT for CSA-AKI is controversial. A substantial number of patients with moderate AKI do not end up requiring RRT when employed only in the case that urgent indications are met. Therefore, there appears to be clear utility of such biomarkers in clinical practice. Further studies, including incorporation of such biomarkers in clinical bundles, are needed with larger patient population.

\section{References}

1. Priyanka P, Zarbock A, Izawa J, Gleason TG, Renfurm RW, Kellum JA. The impact of acute kidney injury by serum creatinine or urine output criteria on major adverse kidney events in cardiac surgery patients. J Thorac Cardiovasc Surg. 2021;162:143-51.e7.

2. Chawla LS, Bellomo R, Bihorac A, Goldstein SL, Siew ED, Bagshaw SM, et al. Acute kidney disease and renal recovery: consensus report of the Acute Disease Quality Initiative (ADQI) 16 Workgroup. Nat Rev Nephrol. 2017;13:241-57.

3. Massoth C, Küllmar M, Enders D, Kellum JA, Forni LG, Meersch M, et al. Comparison of $\mathrm{C}-\mathrm{C}$ motif chemokine ligand 14 with other biomarkers for adverse kidney events after cardiac surgery. J Thorac Cardiovasc Surg. 2023;165:199-207.e2. 